\title{
Control of Acoustic Extinguisher with Deep Neural Networks for Fire Detection
}

\author{
Jacek Lukasz Wilk-Jakubowski ${ }^{1,}$, , Pawel Stawczyk ${ }^{2}$, Stefan Ivanov ${ }^{3}$, Stanko Stankov ${ }^{3}$ \\ ${ }^{1}$ Department of Information Systems, Kielce University of Technology, \\ 7 Tysiaclecia Panstwa Polskiego. Ave, 25-314 Kielce, Poland \\ ${ }^{2}$ Department of Industrial Electrical Engineering, Kielce University of Technology, \\ 7 Tysiaclecia Panstwa Polskiego. Ave, 25-314 Kielce, Poland \\ ${ }^{3}$ Department of Automation, Information and Control Systems, Technical University of Gabrovo, \\ 4 H. Dimitar, Gabrovo, 5300, Bulgaria \\ j.wilk@tu.kielce.pl
}

\begin{abstract}
The search for fast and environmentally safe methods of fighting fires has been a particularly important topic in recent years. Many academic centres are conducting research on the use of Deep Neural Networks to detect flames. One of the most promising is the acoustic method of extinguishing flames. In theory, an acoustic extinguisher can be applied to extinguish fires of different classes because acoustic waves pass through solids, liquids, and gases. In principle, the technology described in the article can be used to extinguish Band C-class fires when gases or liquids are burning. Until now, the known studies have been conducted only for low-power acoustic extinguishers. Therefore, there is a need to fill a theoretical and practical gap in this respect (scientific novelty). The result of the activities is the development of new techniques for extinguishing flames with the use of Deep Neural Networks, and then extinguishing flames using a high and very high power loudspeaker applied to the acoustic extinguisher. The main aim of this paper is to present the possibilities of using Deep Neural Networks to detect fires, as well as the results of research on the extinguishing of flames with the use of square waveforms with Amplitude Modulation (AM) for several frequencies, which is also a scientific novelty, including the minimum acoustic power and sound pressure level as a function of a distance from the output of the acoustic system. On this basis, it became possible to determine the minimum power delivered to the extinguisher and the minimum sound pressure level that causes the extinguishing effect at given input parameters.
\end{abstract}

Index Terms-Acoustic extinguisher; Acoustic testing; Acoustic engineering; Amplitude modulation; Fires; Neural networks; Sound extinguisher.

\section{INTRODUCTION}

Currently, the fire extinguishers filled with an appropriately selected extinguishing agent are used most often to extinguish flames. Its composition is selected depending on the type of fire. Therefore, traditional fire extinguishers are not suitable for universal use in the extinguishing of fires of various materials. Depending on the fire class, fire extinguishers are divided into many groups, some of which are suitable for extinguishing several types of fires. In typical fire extinguishers, the extinguishing

Manuscript received 28 September, 2021; accepted 10 December, 2021. agent is depleted very quickly, recharging the tank is timeconsuming and can only be carried out in designated areas by authorized units. For this reason, conventional fire extinguishers have a number of limitations. Other drawbacks include: adverse impact on the environment and health, damage to equipment during flame extinguishing, the need for periodic pressure tests of tanks, and filling the extinguisher with an extinguishing agent [1]-[3].

The beginnings of the new firefighting technique have roots in the military. The concept of the acoustic extinguisher has become the subject of scientific efforts of the Defense Advanced Research Projects Agency (DARPA), which deals with the daily creation of new technologies for the defense sector in the USA. In 2008, DARPA launched the Instant Fire Suppression (IFS) program, which aimed to find new methods of rapid and effective firefighting [4]. This program was divided into two stages. The first included primarily the analysis of the outbreak of fires and the spread of fires. In addition, it focused on finding the most effective methods of extinguishing flames. The results unequivocally confirmed that the existing firefighting methodology is based on an attempt to interrupt the combustion reaction. Meanwhile, given the physical properties, fire flames can be seen as cold plasma that can be manipulated to extinguish a fire [5], [6]. Based on this, flame extinguishing using electromagnetic and acoustic waves was proposed in the second phase of the project.

At that time, it has been noted that extinguishing flames with acoustic waves is one of the most promising methods. In addition, it has been proven in the past that it is possible to extinguish a fire with an amplified and modulated human voice (using computer techniques). The level of sound pressure exceeds the pain threshold of the human ear. Moreover, two students from the USA - Seth Robertson and Viet Tran - conducted an independent research. After one year of experimentation, they created a sound generator (working at very low frequencies) that can extinguish fires in various situations.

The acoustic extinguishing method using propagation of acoustic waves seems to be not only equally effective, but 
also safer, cheaper to use, and better for the environment than the traditional methods [7]-[15].

It is worth noting that the research so far has been conducted only for low power, so the flames have been extinguished over shorter distances, so there is a need to fill in the gap in this respect [5], [6]. The aim of this paper is to show for cognitive purposes that it is possible to use Deep Neural Networks for flame recognition and use this knowledge to activate an acoustic firefighting system (which seems particularly interesting in the context of further development of firefighting technology). In turn, the scientific novelty of this paper is the presentation of the possibility of extinguishing flames with acoustic waves using square waveforms and Amplitude Modulation (AM), which is the main part of the paper and extends the previous knowledge on this topic. The focus is on the determination of the minimum power delivered to the extinguisher and the minimum sound pressure level causing the extinguishing effect at given input parameters. They are a scientific novelty, as well as the authors' contributions to the disciplines of Automation, Electronics, Electrical Engineering, and Computer Science. Contemporary achievements in signal analysis with the use of computer methods are also important in this field [16]. The results presented in the article were carried out at the Kielce University of Technology and Technical University of Gabrovo.

\section{IDEA OF USING NEURAL NETWORKS FOR FIRE DETECTION}

Fire can be caused by multiple sources, and to prevent the spread of the fire, a fire extinguishing system is needed. Most fire detection systems are based on temperature and smoke sensors. Recently, fires can be detected using a single camera and a well-trained neural network for fire recognition.

Industrial facilities and nature can always be threatened by fires for different reasons. Classical sensors may not always be highly efficient, thus the development of more advanced methods for fire detection is necessary. Artificial Neural Networks (ANN) are very efficient in finding various burning objects by analysing images from thermal cameras [17], [18] and can be used successfully to detect fire [19], [20]. They can replace any expensive sensors by just using a surveillance system. When the fire has been detected, the ANN can automatically show its position in the image.

Recently published papers [21]-[26] related to fire detection present different Convolutional Neural Networks (CNN) networks that can be applied to identify fires and smokes in images and show that they can be applied and combined with various types of algorithms and neural networks in this field.

\section{ARChitecture of MASK R-CNN NEURAL NETWORK AND USED SOFTWARE TECHNOLOGIES}

The mask Region-based Convolutional Neural Network ( $\mathrm{R}-\mathrm{CNN}$ ) is a deep neural network used for solving instance segmentation problems in computer vision separating objects in a video or image. It is based on the Faster R-CNN architecture with two major changes:

- It replaces the Region of Interest pooling (RoI pooling) module with a more accurate RoI Align module;

- An additional branch of the RoI Align module is inserted.

The additional branch accepts the RoI output, and then sends it into the convolutional (Conv) layers. The mask is the output of the convolutional layers. The acquired image is processed by the neural network and recognized objects are masked on the image.

The Mask R-CNN has two stages:

1. To generate proposals where the regions might be in an object based on the input image;

2. To predict the class of the object and refine the bounding boxes generating a pixel-level mask of the object in the first proposal.

This network is a Feature Pyramid Network (FPN) style Deep Neural Network. The FPN outperforms other single ConvNets mainly for the reason that it maintains strong semantical features at various resolution scales. The structure of the Mask R-CNN is presented in Fig. 1.

The neural network is an extension to the Faster R-CNN. The faster R-CNN can only predict bounding boxes, while the Mask R-CNN in parallel predicts the object mask.

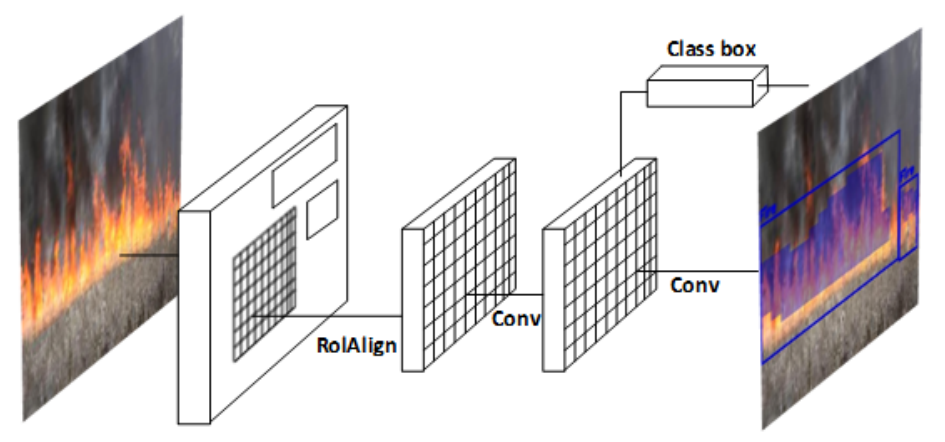

Fig. 1. Mask R-CNN framework for instance segmentation.

To implement the neural network for fire detection, several software technologies are used. For image processing, Opencv is applied, which is an open source computer vision and machine learning library. It is designed to provide a common vision application infrastructure and speed up machine perception. The library has more than 2,500 optimized algorithms that include a comprehensive set of classic and advanced computer vision and machine learning algorithms [27].

NumPy [28] is a library for the Python programming 
language, which supports multidimensional arrays. Using NumPy, we can display the images as multidimensional arrays. NumPy has built-in high-level mathematical arrays that allow for an accurate mathematical analysis of the image in a quick and easy way.

Matplotlib [29] is a separate library that is used for different types of visualization in Python. When analyzing an image, Matplotlib is applied regardless of whether it separates the image from histograms or simply opens the image itself.

Imutils [30] is a library with common features, such as rotation and resizing of the image.

TensorFlow [31] is a comprehensive open source platform for machine learning. It has a flexible ecosystem of tools, libraries, and social resources that allows researchers to push the boundaries of the state-of-the-art machine learning and allows programmers to easily build and deploy machine learning applications.

\section{TRAINING THE NEURAL NETWORK}

A neural network has been trained with the Mask R-CNN architecture, which has a high speed for detecting various objects [32]. Training of the neural network for fire detection has been done with 120 images. These images using a Python script are multiplied by number through translation and scaling operations and brightness adjustment. In this way, there are automatically generated 3600 images with different positions of the fires in the images. The searcher algorithm extracts their characteristics and pixel annotations and trains the neural network with Mask R-CNN Inception architecture for 45000 cycles until reaching the desired accuracy. In practice, the training requires an initial database of photographs (some of them are shown in Fig. 2), from which it is necessary to extract the characteristics of objects, which must be found later. This also involves creating a mask annotation in each image.

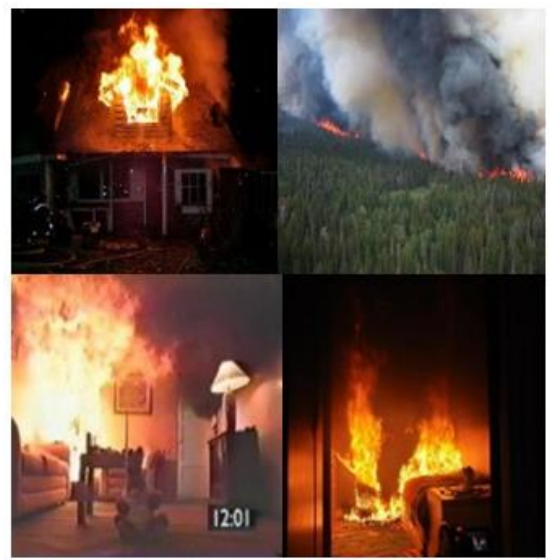

Fig. 2. Examples of photos for neural network training.

As mentioned earlier, the neural network is trained using the library for machine learning TensorFlow. The training is carried out with the help of a Graphics Processing Unit (GPU) device - GTX1080Ti. The neural network is capable of recognizing many objects, and by software filtering, it is possible to select which object from the list of the trained objects is a fire and which is not in the image [33].
The well-trained neural network is possible to be implemented in various processing systems with Central Processing Unit (CPU), GPU, and Vision Processing Unit (VPU). The NVIDIA Jetson Nano kit is used for the current implementation in Fig. 3. The system includes a USB camera for real-time detection, an HDMI display, and relays for control signals to the external extinguisher.

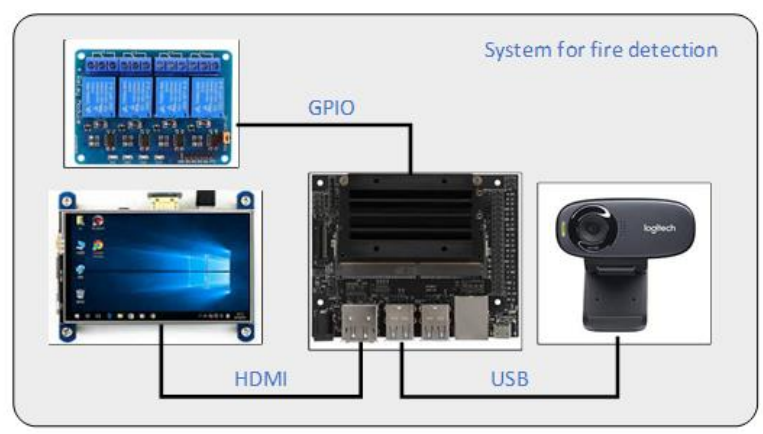

Fig. 3. System with Jetson Nano kit and peripherals.

The Jetson Nano board is a developer kit, which consists of a System on Module (SoM) and the reference carrier board. It is primarily designed to create embedded systems that require high computing power for machine learning, machine vision, and video processing applications [34], [35]. The board has a camera interface that can be used for real-time fire detection and General-Purpose Input/Output (GPIO) pins that can be applied to control fire extinguishers. The trained model is transferred to the memory of NVIDIA Jetson Nano. The model transferred in Jetson Nano is the same as the model trained with the help of the GPU, and it is used to detect fire in the test images.

\section{Detection OF Flames}

The neural network has been tested on 400 images that were not included in the training, and the accuracy of the detection is $86 \%$, as the errors include false positive and false negative responses of the neural network.

Figure 4 shows the fire detection in the image for basic testing without other objects in it.

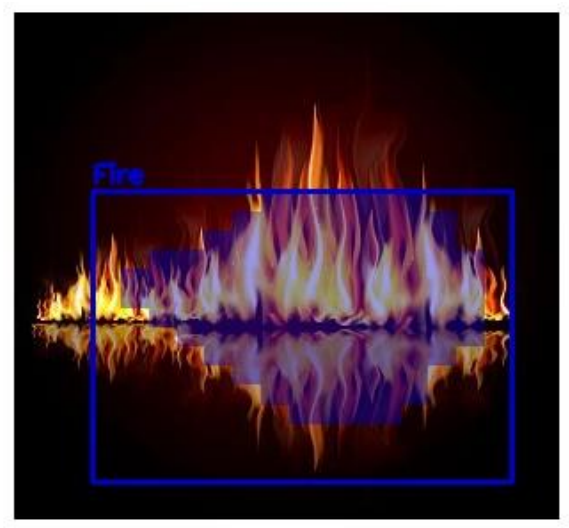

Fig. 4. Fire detection of an image with dominant fire source.

The second test of the neural network used the image of fire in the living room. The image shows objects of the same color as the fire. Even under these conditions, the neural network is able to separate the fire from the other objects. The test results are shown in Fig. 5. 


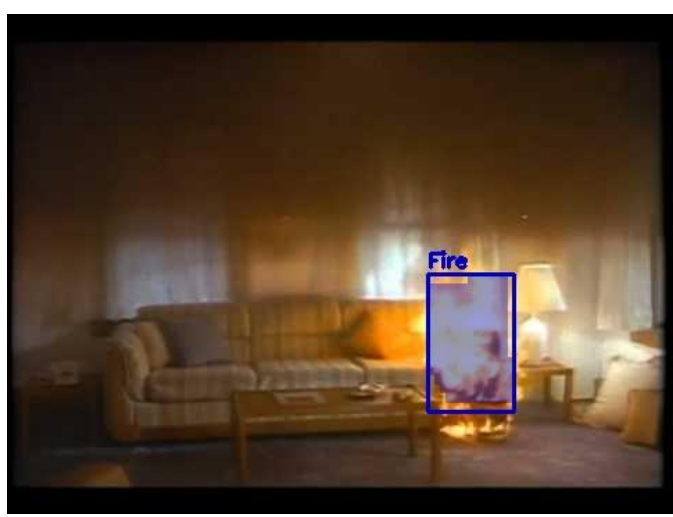

Fig. 5. Fire detection in a living room.

The third test photo was of a roof that burned during the day. As shown in Fig. 6, neural networks detect fires successfully.

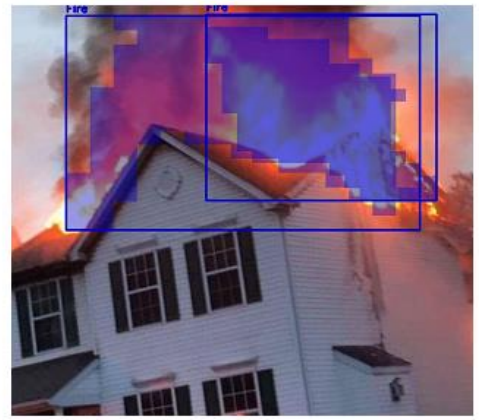

Fig. 6. Fire detection in a burning house.

Since all previously used test photos are static, it is worth checking out the performance of a trained neural network in real-time. Similarly, for this purpose, the videos of fires downloaded from YouTube by researchers from Technical University of Gabrovo were used. These videos show fires of varying degrees of intensity. The tests of these videos have demonstrated the ability of neural networks to recognize the presence of fire in video streams.

A snapshot from a video with burning objects detected by the neural network is shown in Fig. 7.

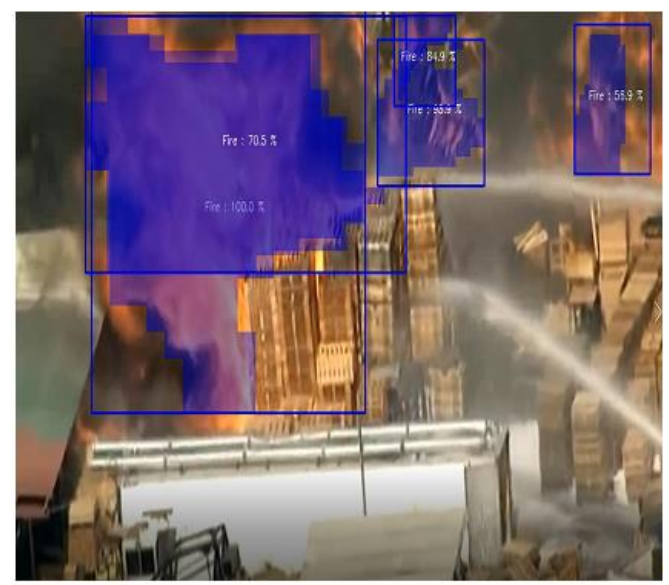

Fig. 7. A snapshot of a video signal with real-time fire detection.

As shown above, the proposed neural network is reliable in the detection of fires and can be integrated into modern fire protection systems without any other sensors. The advantages of this fire detection system are the relatively low cost of the components used and the commercially available high-performance fire detection technologies. This system can be applied in high temperature facilities, such as foundries, sand dryers, and heat treatment factories where other types of sensors are not suitable for fire detection.

It should be noted that robotics along with artificial intelligence finds application in crisis management [36]. It is possible to combine a video fire detection system with the external, non-invasive, high acoustic power extinguisher, whose construction is presented in the next section (scientific novelty). This method is perfect for detecting and extinguishing fires at the first stage of their occurrence, e.g., in production halls, dedicated equipment exposed to the occurrence of flames, etc.

\section{MeAsurement Station fOR EXTINGUishing FlameS WITH ACOUSTIC WAVES}

As mentioned above, the acoustic power is also an essential parameter. To date, the research has focused on the use of acoustic waves of very low power, which allows one to extinguish flames only in a short distance from the output of the system [5], [6]. The research has shown that effective extinguishing tests have been carried out using only lowfrequency acoustic waves. The use of high and very high acoustic power allows us to extend this distance, while the use of a camera for video monitoring of the object with computer techniques allows us to fast and accurate detection of potential flames. This is due to the fact that the effectiveness of the extinguishing process depends on the amplitude of the air vibrations.

The measurement station consists of: Rigol DG4102 generator with AM modulation function, Proel HPX2800 power amplifier, and acoustic extinguisher. As a sound level meter, SVAN 979 was used. The construction of the acoustic extinguisher is shown in Fig. 8.

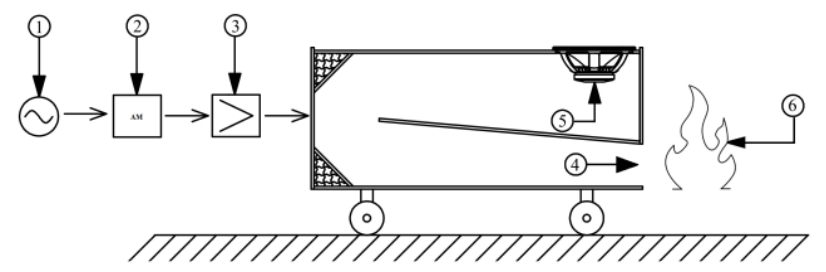

Fig. 8. Experimental acoustic extinguisher: 1) signal generator, 2) AM modulator, 3) high and very high power amplifier, 4) waveguide output (extinguisher output), 5) dedicated bass speaker, 6) source of fire.

At the beginning of the waveguide, a B\&C 21DS115 loudspeaker with a nominal power of $1700 \mathrm{~W}$ was installed. From a theoretical point of view, the required waveguide length is twice as short in a closed end tube [37]. Both modulated and unmodulated waveforms can be used for extinguishing [38]-[41]. For low frequencies, a significant wavelength is required, e.g., for sound waves at $20 \mathrm{~Hz}$ the required wavelength is equal to $\lambda_{1}=4.28 \mathrm{~m}$ for a closed end tube and $\lambda_{2}=8.57 \mathrm{~m}$ for an open end tube. Thus the acoustic extinguisher is made as a waveguide with a single tunnel bend with a rectangular section of $4.28 \mathrm{~m}$ in length so that the full power of the speaker can be used. In practice, the standing wave nodes are formed at the open end of the resonant tube, while the arrows are formed at the closed end of the tube. With increasing distance from the closed end of 
the tube, the acoustic pressure decreases to a minimum at the open end of the tube (waveguide output) [39], [40]. During the measurements, the extinguishing device was powered by a high-power acoustic amplifier to the input of which the waveform was tested with parameters: $1 \mathrm{~V}$ RMS, $1 \mathrm{~V}$ RMS $\times 2 \sqrt{2}=2.828 \mathrm{~V}$ (peak-to-peak value). On this basis, it became possible to determine the minimum Power (P) delivered to the extinguisher causing the extinguishing effect, as well as the minimum Sound Pressure Level (SPL) causing the extinguishing effect at given input parameters (specified distance $\mathrm{L}$ from the output of the acoustic extinguisher for several frequencies).

Figure 9 shows the transmission characteristics of the fire extinguisher. During measurement, the microphone was located at a distance of $1 \mathrm{~m}$ from the extinguisher output on the axis of the set according to the AES2-1984 standard. The length of the waveguide was designed to ensure effective emission of acoustic waves with frequencies in the range of $15 \mathrm{~Hz}-20 \mathrm{~Hz}$ (for a single-sided closed waveguide, this length is $4.28 \mathrm{~m}$ ). The parameters of the extinguisher were detailed in the article [39].

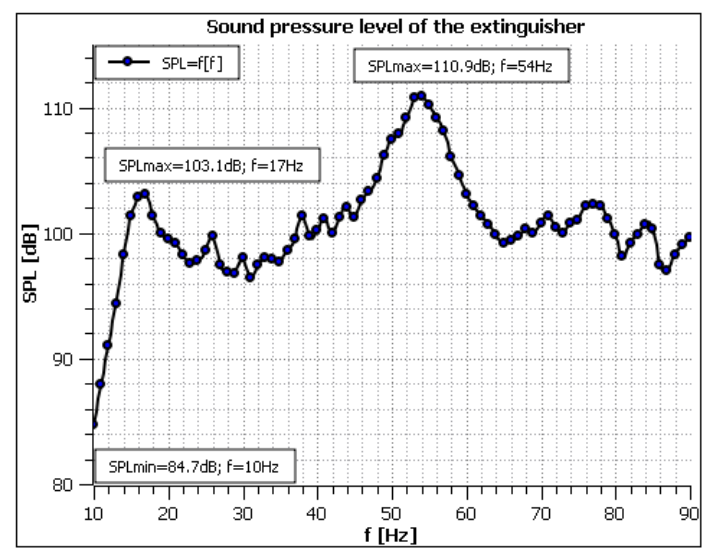

Fig. 9. Sound pressure level curve of the extinguisher [39].

The acoustic background noise during the measurements was equal to $64.7 \mathrm{~dB}$. This value presents a sound pressure level just before the measurements. In practice, the noise level is a random variable. Therefore, it becomes possible to determine the probability that a temporary noise level belongs to a given range. $\mathrm{LN} \%$ is understood to be some limiting level exceeded by the background noise in no more than $\mathrm{N} \%$ of the observation time (see the data in Table I below).

TABLE I. LISTING OF THE LIMITING LEVELS (LN \%) EXCEEDED BY THE TEMPORARY NOISE LEVEL IN NO MORE THAN N \% OF THE OBSERVATION PERIOD.

\begin{tabular}{|c|c|c|}
\hline & $\mathbf{1}$ & $\mathbf{2}$ \\
\hline $\mathbf{1}$ & Profile & P1 (Z, Slow) \\
\hline $\mathbf{2}$ & Ln & Lzeq Ln spectra [dB] \\
\hline $\mathbf{3}$ & L10 & 63.0 \\
\hline $\mathbf{4}$ & L20 & 68.6 \\
\hline $\mathbf{5}$ & L30 & 66.7 \\
\hline $\mathbf{6}$ & L40 & 65.4 \\
\hline $\mathbf{7}$ & L50 & 64.5 \\
\hline $\mathbf{8}$ & L60 & 63.7 \\
\hline $\mathbf{9}$ & L70 & 62.7 \\
\hline $\mathbf{1 0}$ & L80 & 61.9 \\
\hline $\mathbf{1 1}$ & L90 & 61.1 \\
\hline $\mathbf{1 2}$ & L95 & 60.5 \\
\hline
\end{tabular}

For example, during the measurements, the $73 \mathrm{~dB}$ background noise level was exceeded by no more than $10 \%$ of the observation time, while the $60.5 \mathrm{~dB}$ level was exceeded by no more than $95 \%$ of the observation period.

It should be noted that all measurements were made at the same time and under the same weather conditions, so the results are meaningful. $\mathrm{Z}$ filter was used according to IEC $61672-1$. The integration period was equal to $15 \mathrm{~s}$. To obtain the most stable background noise level possible, averaging of the result over a specified time interval of $1 \mathrm{~s}$ was applied. It means that the results were averaged every $1 \mathrm{~s}$.

In these experiments, the sources of the flames were burning candles. When a candle is used, as opposed to a diffuse fire source, such as one using a gas-fueled mock-up, it is clear whether the flames were extinguished. In the experiments with the gaseous fuel mock-up, it could be observed that if sometimes the flames were not completely extinguished, they would be reignited. Therefore, it was considered that a point source, such as a candle, would allow the extinguishing process to be clearly observed. The flame height was approximately equal to $20 \mathrm{~mm}$.

\section{EXPERIMENTAL RESULTS OF THE INFLUENCE OF THE SOUND FREQUENCY ON THE EXTINGUISHING EFFECT}

Flame extinguishing is possible not only with unmodulated acoustic waves, but also with modulated waves, which has been confirmed experimentally [38]-[41]. A scientific novelty besides the use of high and very high acoustic powers is the presentation of results on the possibility of extinguishing flames with the use of AM modulated waveforms. Such tests were carried out in Kielce as a part of the project "InIn+" (No. 3/2017), which was cofinanced by the Ministry of Science and Higher Education. The results concerning the electrical power supplied to the loudspeaker (capable to extinguish the flames) and the sound pressure level as a function of distance from the extinguisher output $(0.1 \mathrm{~m}, 0.3 \mathrm{~m}, 0.5 \mathrm{~m}$, and $0.7 \mathrm{~m})$, at the three analysed frequencies: $15 \mathrm{~Hz}, 17 \mathrm{~Hz}$, and $20 \mathrm{~Hz}$, for a sinusoidal waveform modulated by a square waveform (AM modulation, $\mathrm{f}_{\mathrm{MOD}}=\mathrm{f}_{\mathrm{MFreq}}=0.125 \mathrm{~Hz}=$ const . ) are presented below. The authors' intention was to present minimum sound pressure levels at which the extinguishing effect was observed, as well as minimum power delivered to the extinguisher, causing the effect of extinguishing as a function of the selected input parameters. Therefore, each measurement was treated individually and evaluated. It is worth noting that the flames have not been extinguished in the frequency range of $10 \mathrm{~Hz}-13 \mathrm{~Hz}$.

The results for the frequency of $15 \mathrm{~Hz}$ depending on the distance of the extinguisher output are presented in Fig. 10.

On this background, the results concerning the minimal Sound Pressure Level (SPL) causing the extinguishing effect as a function of the distance (L) from the output of the extinguisher are very interesting (Fig. 11).

The results for the frequency of $17 \mathrm{~Hz}$ depending on the distance of the extinguisher output are presented in Fig. 12.

The minimal SPL causing the extinguishing effect as a function of the distance from the output of the extinguisher for the frequency of $17 \mathrm{~Hz}$ is presented in Fig. 13. 


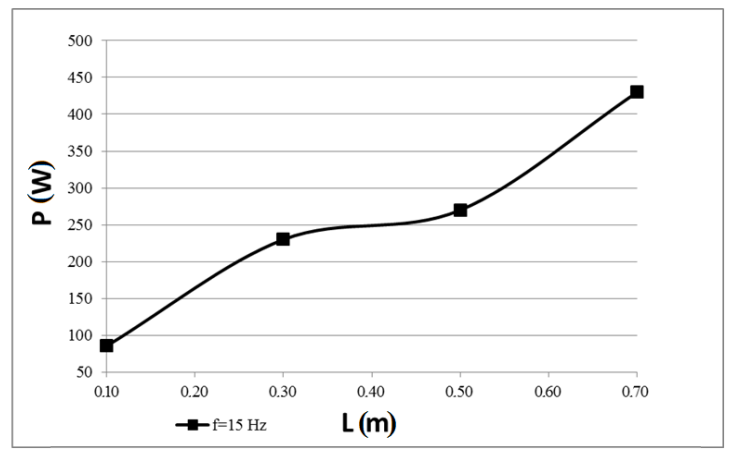

Fig. 10. Minimal power (P) delivered to the fire extinguisher causing the extinguishing effect as a function of the distance (L) from the fire extinguisher output for the frequency of $15 \mathrm{~Hz}$.

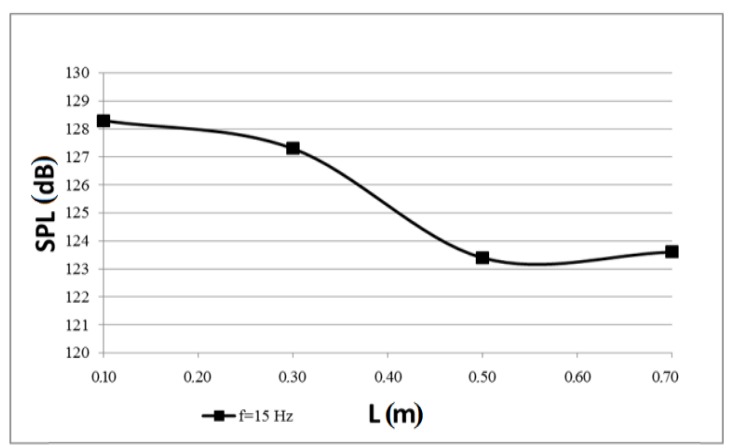

Fig. 11. Minimal SPL causing the extinguishing effect as a function of the distance (L) from the fire extinguisher output for the frequency of $15 \mathrm{~Hz}$.

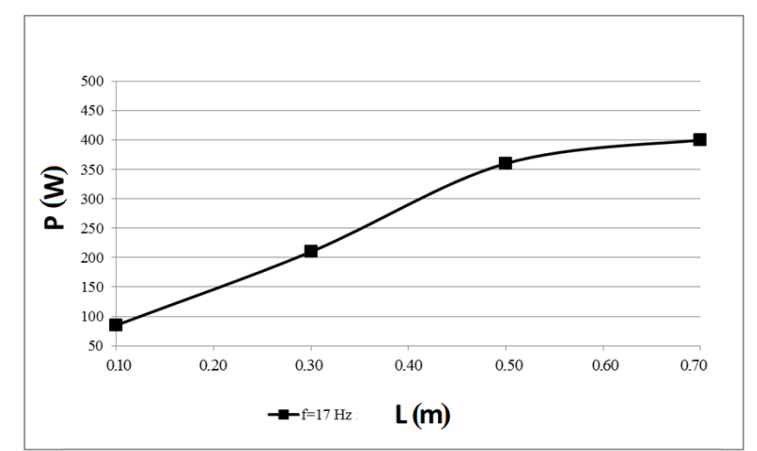

Fig. 12. Minimal power (P) delivered to the fire extinguisher causing the extinguishing effect as a function of the distance (L) from the fire extinguisher output for the frequency of $17 \mathrm{~Hz}$.

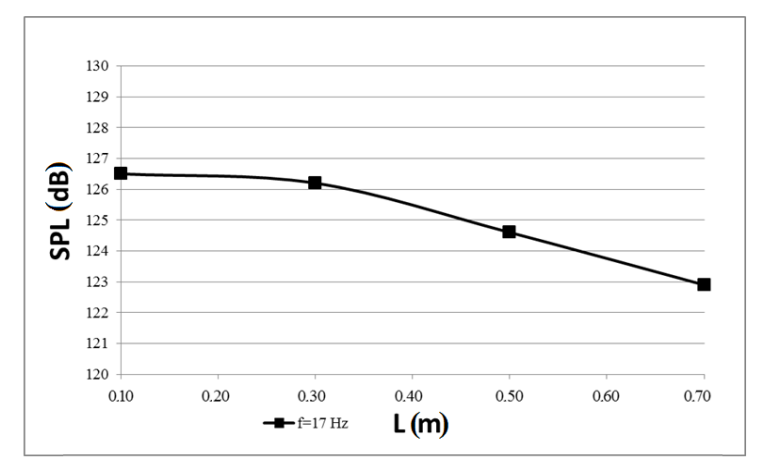

Fig. 13. Minimal SPL causing the extinguishing effect as a function of the distance (L) from the fire extinguisher output for the frequency of $17 \mathrm{~Hz}$.

The results for the last frequency analysed in this study, i.e., $20 \mathrm{~Hz}$ depending on the distance of the extinguisher output, are shown in Fig. 14.

For this frequency, the diagram of the minimum SPL that causes the extinguishing effect as a function of the distance from the extinguisher output is presented in Fig. 15.

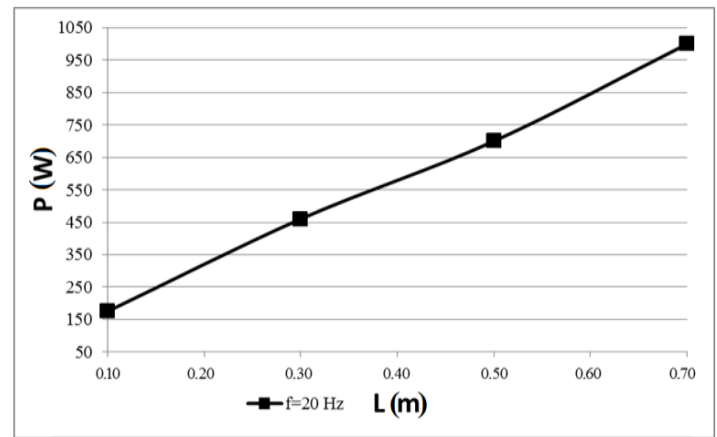

Fig. 14. Minimal power $(\mathrm{P})$ delivered to the fire extinguisher causing the extinguishing effect as a function of the distance (L) from the fire extinguisher output for the frequency of $20 \mathrm{~Hz}$.

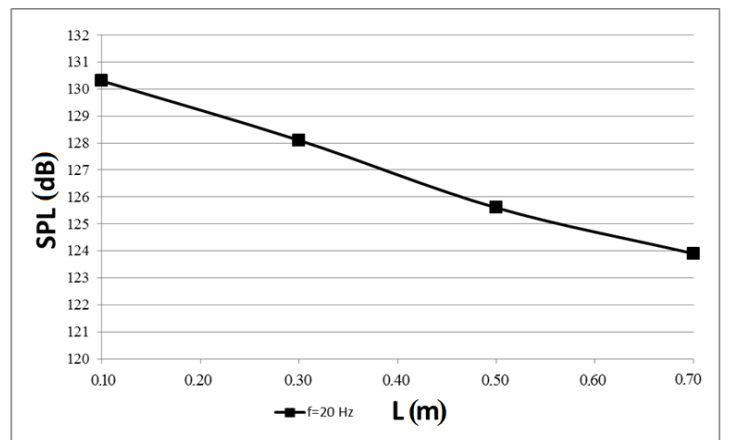

Fig. 15. Minimal SPL causing the extinguishing effect as a function of the distance (L) from the fire extinguisher output for the frequency of $20 \mathrm{~Hz}$.

The article clearly proves that the effect of extinguishing the acoustic waves depends on the frequency of the acoustic waves. As the distance increases, more power is needed at the source of the sound to extinguish the flames. This phenomenon was observed for each of the frequencies analysed. On the other hand, the measured sound pressure levels decrease inversely proportional to the square of the distance from the source with an increase in the distance from the fire extinguisher output.

\section{CONCLUSIONS}

The proposed neural network is reliable for fire detection and can be integrated into modern fire protection systems, replacing other sensors. The advantage of the system is that it uses relatively inexpensive components and high flame detection accuracy as the vision system. It should be noted that this system can be used in high-temperature facilities, such as foundries, sand dryers, and heat treatment factories where other types of sensors are not suitable for fire detection.

A non-invasive project of acoustic extinguisher using natural mechanisms of sound wave propagation to extinguish flames is a response to the search for innovative solutions for extinguishing flames. The result of the joint activities carried out at the Kielce University of Technology and the Technical University of Gabrovo tends toward the development of new techniques for extinguishing flames with the use of Deep Neural Networks, and then extinguishing flames using a high and very high power loudspeaker applied to the acoustic extinguisher [38]-[42]. Moreover, other scientific efforts have resulted in some inventions that add to the state-of-the-art, e.g., [43]-[48].

The research presented in this paper has confirmed the 
effectiveness of flame extinguishing using a high-power acoustic extinguisher and AM modulated waveforms. It was shown that acoustic waves with lower frequencies cause higher amplitudes of flame oscillations, and thus show good effectiveness in extinguishing flames. Therefore, the use of long waveguides is recommended, but it is associated with technical problems. A key issue, especially when using mobile extinguishers, is their size (the aim of designers is to reduce the dimensions of the extinguisher as much as possible). Acoustic waves are emitted omnidirectionally, but the main acoustic stream is located in the axis of the waveguide. Undoubtedly, the dispersion of the acoustic beam reduces the distance from successful fire extinguishing [39].

The range of possible applications with direct human involvement limits the impact of low-frequency acoustic waves on human health. Therefore, careful analyses are needed in this regard. The benefit of using the acoustic extinguisher activated by the neural networks, proposed in this paper, is the possibility of replacing traditional fire protection measures with an acoustic extinguisher in the future. However, to make this possible, a lot of research is still needed, including, e.g., studies focused on the impact of other waveforms, modulations, and fire sources. Another issue is determining the effect of low-frequency waves on building structures. On the other hand, autonomous firefighting systems equipped with artificial intelligence and modular robots that operate without human intervention can be used in crisis situations [36]. This is especially important as there has been a year-over-year increase in crisis management spending [49]. For the analysis of development trends, methods known from economic sciences may be applied [49], [50]. In addition, a fire extinguisher can be an additional (supportive) protection mean. Its unquestionable advantage over traditional solutions is the non-invasive character of its operation. Currently used hand-held extinguishing agents (e.g., extinguishing foam, extinguishing powder, and hand-pump extinguishers) may cause damage to room or vehicle equipment (including the electrical system). As many other studies have shown, some of the solutions are harmful to health (e.g., halon extinguisher, which is filled with liquid with a very low vaporization temperature). Since harmful gases are emitted during fire extinguishing, the use of such extinguishers is now being phased out. A better solution seems to be the use of extinguishing blankets. However, in the case of a significant fire, the fire extinguishing blanket is not very effective and dangerous, especially for persons in the fire zone (due to the formation of uncontrolled air blasts caused by the movement of the extinguishing agent, which causes the possibility of burning the person and the spread of fire).

In summary, the technique proposed by the authors to extinguish flames with the use of neural network-controlled acoustic waves may constitute an essential element of equipment, permanently installed in rooms and vehicles, and dedicated equipment exposed to the occurrence of flames. The technology described in the article may, in the future, be, among others, a technique supporting the safety of industrial halls. Contemporary research on image recognition, including computer analysis of data from camera monitoring, e.g., buildings and devices, is also crucial in this respect. The technology of extinguishing flames with acoustic waves can become the element that supports the fire protection of warehouses or tanks of flammable liquids. The unquestionable advantages of this solution are the diametrically lower costs of firefighting and exploitation than in the case of typical traditional methods.

\section{ACKNOWLEDGMENT}

The authors would like to thank the company "Ekohigiena Aparatura Ryszard Putyra Sp.J.", 19 Strzelecka St., 55-300 Środa Śląska, Poland, and "Przedsiębiorstwo Handlowo-Techniczne SUPON Sp. z o.o.”, 105 Sandomierska St., 25-324 Kielce, Poland, for their support in the realization of the research.

\section{STATEMENT}

It is the intention of authors to include this work in the support provided by National Science Center (Narodowe Centrum Nauki) under the Miniatura 5 grant entitled "Environmentally friendly methods for extinguishing flames on the basis of the acoustic method" ("Przyjazne dla środowiska metody gaszenia płomieni na przykładzie metody akustycznej"), in the framework of the conducted research.

\section{CONFLICT OF INTEREST}

The authors declare that they have no conflicts of interest.

\section{REFERENCES}

[1] G. Jensen, Manual Fire Extinguishing Equipment for Protection of Heritage. Oslo: COWI AS, 2006.

[2] K. Radwan and J. Rakowska, "Analiza skuteczności zastosowania wodnych roztworów mieszanin koncentratów pianotwórczych do gaszenia pożarów cieczy palnych", Przemyst Chemiczny, vol. 90, no. 12, pp. 2118-2121, 2011.

[3] W. Wnęk, P. Kubica, and M. Basiak, "Standardy projektowania urządzeń gaśniczych tryskaczowych - Porównanie głównych parametrów", Bezpieczeństwo i Technika Pożarnicza, vol. 27, no. 3 , pp. 83-96, 2012.

[4] DARPA sound based fire extinguisher, Defense Advanced Research Projects Agency. [Online]. Available: https://www.extremetech.com/extreme/132859-darpa-creates-soundbased-fire-extinguisher

[5] T. Węsierski, S. Wilczkowski, and H. Radomiak, "Wygaszanie procesu spalania przy pomocy fal akustycznych", Bezpieczeństwo $i$ Technika Pożarnicza, vol. 30, no. 2, pp. 59-64, 2013.

[6] H. Radomiak, M. Mazur, M. Zajemska, and D. Musiał, "Gaszenie płomienia dyfuzyjnego przy pomocy fal akustycznych", Bezpieczeństwo i Technika Pożarnicza, vol. 40, no. 4, pp. 29-38, 2015. DOI: 10.12845/bitp.40.4.2015.2.

[7] A. N. Friedman, P. I. Danis, G. J. Fiola, C. A. Barnes, and S. I Stoliarov, "Acoustically enhanced water mist suppression of heptane fueled flames”, Fire Technology, vol. 54, pp. 1829-1840, 2018. DOI: 10.1007/s10694-018-0777-0.

[8] A. S. Sharan, S. Akanksh, R. K. Mohan Ram, and H. R. Uttunga, "Development of portable fire extinguisher using acoustic waves", Bapuji Institute of Engineering and Technology, Project reference No. 39_BE_1977. [Online]. Available: http://www.kscst.iisc.ernet.in/spp/39_series/SPP39S/02_Exhibition_Pro jects/196_39S_BE_1977.pdf

[9] B.-Y. Kim, M.-J. Bae, and S.-G. Bae, "A study on suitability of sound fire extinguisher in duct environment", International Journal of Applied Engineering Research, vol. 12, no. 24, pp. 15796-15800, 2017.

[10] M.-S. Kim and M.-J. Bae, "A study on a fire extinguisher with sound focus”, Information (Japan), vol. 20, no. 6, pp. 4055-4062, 2017.

[11] R. T. Sai and G. Sharma, "Sonic fire extinguisher", Pramana 
Research Journal, vol. 8, no. 11, pp. 337-345, 2018.

[12] E.-Y. Ji, U.-J. Song, and M.-J. Bae, "A study on the directionality of sound fire extinguisher in electric fire", Convergence Research Letter of Multimedia Services Convergent with Art, Humanities, and Sociology, vol. 3, no. 4, pp. 1449-1452, 2017.

[13] P. Niegodajew, K. Gruszka, R. Gnatowska, and M. Šofer, "Application of acoustic oscillations in flame extinction in a presence of obstacle", Journal of Physics: Conference Series, vol. 1101, 2018. DOI: 10.1088/1742-6596/1101/1/012023.

[14] A. Noga, "Przegląd obecnego stanu wiedzy z zakresu techniki infradźwiękowej i możliwości wykorzystania fal akustycznych do oczyszczania urządzeń energetycznych", Zeszyty Energetyczne, vol. 1, pp. 225-234, 2014

[15] A. Jędrusyna and A. Noga, "Wykorzystanie generatora fal infradźwiękowych dużej mocy do oczyszczania z osadów powierzchni grzewczych kotłów energetycznych", Piece Przemystowe \& Kotty, vols. 11-12, pp. 30-37, 2012.

[16] L. Šerić, D. Stipaničev, and D. Krstinić, "ML/AI in intelligent forest fire observer network", in Proc. of Third EAI International Conference on Management of Manufacturing Systems, 2018. DOI: 10.4108/eai.6-11-2018.2279681.

[17] Ch. Szegedy, A. Toshev, and D. Erhan, "Deep neural networks for object detection", Advances in Neural Information Processing Systems, vol. 26, pp. 1-9, 2013.

[18] D. Foley and R. O'Reilly, "An evaluation of convolutional neural network models for object detection in images on low-end devices", in Proc. of The 26th AIAI Irish Conference on Artificial Intelligence and Cognitive Science, 2018, pp. 350-361.

[19] P. Janků, Z. Komínková Oplatková, T. Dulík, P. Snopek, and J. Líba, "Fire detection in video stream by using simple artificial neural network", Mendel, vol. 24, no. 2, pp. 55-60, 2018. DOI: 10.13164/mendel.2018.2.055

[20] A. R. Kurup, "Vision based fire flame detection system using optical flow features and artificial neural network", International Journal of Science and Research, vol. 3, no. 10, pp. 2161-2168, 2014.

[21] P. Li and W. Zhao, "Image fire detection algorithms based on convolutional neural networks", Case Studies in Thermal Engineering, vol. 19, art. ID 100625, 2020. DOI: 10.1016/j.csite.2020.100625.

[22] P. Li, Y. Yang, W. Zhao, and M. Zhang, "Evaluation of image fire detection algorithms based on image complexity", Fire Safety Journal, vol. 121, art. ID 103306, 2021. DOI 10.1016/j.firesaf.2021.103306.

[23] S. Sudhakar, V. Vijayakumar, C. Sathiya Kumar, V. Priya, L. Ravi, and V. Subramaniyaswamy, "Unmanned Aerial Vehicle (UAV) based Forest Fire Detection and monitoring for reducing false alarms in forest-fires", Computer Communications, vol. 149, pp. 1-16, 2020 DOI: 10.1016/j.comcom.2019.10.007.

[24] F. Bu and M. Samadi Gharajeh, "Intelligent and vision-based fire detection systems: A survey", Image and Vision Computing, vol. 91, art. ID 103803, 2019. DOI: 10.1016/j.imavis.2019.08.007.

[25] L. He, X. Gong, S. Zhang, L. Wang, and F. Li, "Efficient attention based deep fusion CNN for smoke detection in fog environment", Neurocomputing, vol. 434, pp. 224-238, 2021. DOI 10.1016/j.neucom.2021.01.024

[26] X. Song, S. Gao, X. Liu, and Ch. Chen, "An outdoor fire recognition algorithm for small unbalanced samples", Alexandria Engineering Journal, vol. 60, no. 3, pp. 2801-2809, 2021. DOI: 10.1016/j.aej.2021.01.028.

[27] R. Laganiere, Opencv 3 Computer Vision Application Programming Cookbook, 3rd ed. Birmingham: Packt Publishing, 2017.

[28] NumPy quickstart, NumPy. [Online]. Available: https://numpy.org/doc/stable/user/quickstart.html

[29] Overview, Matplotlib 3.4.3. [Online]. Available: https://matplotlib.org/stable/contents.html

[30] PyImageSearch/imutils, Github. [Online]. Available: https://github.com/jrosebr1/imutils

[31] An end-to-end open source machine learning platform, TensorFlow. [Online]. Available: https://www.tensorflow.org/

[32] X. Zhang, "Simple understanding of Mask RCNN", 22 Apr., 2018.
[Online]. Available: https://medium.com/@alittlepain833/simpleunderstanding-of-mask-rcnn-134b5b330e95

[33] L. Weng, "Object Detection for Dummies Part 3: R-CNN Family", 31 Dec., 2017. [Online]. Available: https://lilianweng.github.io/lil$\log / 2017 / 12 / 31 /$ object-recognition-for-dummies-part-3.html\#roipooling

[34] Jetson Nano Developer Kit, User Guide, NVIDIA, DA_09402_002, 8 Jul., 2019.

[35] E. Wu, "NVIDIA Jetson Nano Developer Kit Detailed Review", 3 Apr., $2019.2 \quad$ [Online]. Available: https://www.seeedstudio.com/blog/2019/04/03/nvidia-jetson-nanodeveloper-kit-detailed-review

[36] G. Wilk-Jakubowski, R. Harabin, and S. Ivanov, "Robotics in crisis management: A review of the literature", to be published in Technology in Society, 2021.

[37] F. Hausdorf, Podręcznik Budowy Zestawów Gtośnikowych. Poznań: VISATON, 1996

[38] S. Ivanov, S. Stankov, J. Wilk-Jakubowski, and P. Stawczyk, "The using of Deep Neural Networks and acoustic waves modulated by triangular waveform for extinguishing fires", in New Approaches for Multidimensional Signal Processing. Smart Innovation, Systems and Technologies, vol. 216. Springer, Singapore, 2021. DOI 10.1007/978-981-33-4676-5_16.

[39] P. Stawczyk and J. Wilk-Jakubowski, "Non-invasive attempts to extinguish flames with the use of high-power acoustic extinguisher", Open Engineering, vol. 11, no 1, pp. 349-355, 2021. DOI 10.1515/eng-2021-0037.

[40] J. Wilk-Jakubowski, P. Stawczyk, S. Ivanov, and S. Stankov, "The using of Deep Neural Networks and natural mechanisms of acoustic waves propagation for extinguishing flames", to be published in International Journal of Computational Vision and Robotics, 2021 DOI: 10.1504/IJCVR.2021.10037050.

[41] J. Wilk-Jakubowski, P. Stawczyk, S. Ivanov, and S. Stankov, "Highpower acoustic fire extinguisher with artificial intelligence platform", to be published in International Journal of Computational Vision and Robotics, 2021. DOI: 10.1504/IJCVR.2021.10039861.

[42] J. Wilk-Jakubowski, "Analysis of flame suppression capabilities using low-frequency acoustic waves and frequency sweeping techniques", Symmetry (Multidimensional Signal Processing and Its Applications), vol. 13, no 7, p. 1299, 2021. DOI: 10.3390/sym13071299.

[43] S. Wilczkowski, L. Szecówka, H. Radomiak, and K. Moszoro, "Urządzenie do gaszenia płomieni falami akustycznymi (System for suppressing flames by acoustic waves)" - patent, PAT.177478, No application: P.311910, 1999.

[44] S. Wilczkowski, L. Szecówka, H. Radomiak, and K. Moszoro, "Sposób gaszenia płomieni falami akustycznymi (The method of extinguishing flames with acoustic waves)" - patent, PAT.177792, No application: P.311909, 2000.

[45] J. Wilk-Jakubowski, "Urządzenie do gaszenia płomieni falami akustycznymi (Device for flames suppression with acoustic waves)" patent, PAT.233025, No application: P.427999, 2018

[46] J. Wilk-Jakubowski, "Urządzenie do gaszenia płomieni falami akustycznymi (Device for flames suppression with acoustic waves)" patent, PAT.233026, No application: P.428002, 2018.

[47] J. Wilk-Jakubowski, "Urządzenie do gaszenia płomieni falami akustycznymi (System for suppressing flames by acoustic waves)" utility model, RWU.070441, No application: W.127019, 2018.

[48] J. Wilk-Jakubowski, "Urządzenie do gaszenia płomieni falami akustycznymi (Device for flames suppression with acoustic waves)" patent, PAT.234266, No application: P.428615, 2019.

[49] G. Wilk-Jakubowski, Normative Dimension of Crisis Management System in the Third Republic of Poland in an International Context. Organizational and Economic Aspects. Łódź-Warszawa: Wydawnictwo Społecznej Akademii Nauk, 2019.

[50] M. Marek, "Wykorzystanie ekonometrycznego modelu klasycznej funkcji regresji liniowej do przeprowadzenia analiz ilościowych w naukach ekonomicznych", in Rola informatyki $w$ naukach ekonomicznych $i$ spolecznych. Innowacje $i$ implikacje interdyscyplinarne. Kielce: Wydawnictwo Wyższej Szkoły Handlowej im. B. Markowskiego w Kielcach, 2013.

This article is an open access article distributed under the terms and conditions of the Creative Commons Attribution 4.0 (CC BY 4.0) license (http://creativecommons.org/licenses/by/4.0/) 